\title{
THE CORONAVIRUS REPLICASE: INSIGHTS INTO A SOPHISTICATED ENZYME MACHINERY
}

\author{
John Ziebuhr*
}

\section{INTRODUCTION}

The order Nidovirales currently comprises three families of plus-strand RNA viruses, the Coronaviridae, Arteriviridae, and Roniviridae, which are thought to have a common phylogenetic origin. ${ }^{1-3}$ The proposed close phylogenetic relationship between the three virus families is mainly based upon common features that discrimate nidoviruses from other RNA plus-strand RNA viruses, including (i) the production of a nested set of 3'coterminal subgenome-length RNAs, ${ }^{4}$ (ii) the use of ribosomal frameshifting into the -1 reading frame to express the key replicative functions, ${ }^{5}$ and (iii) the conservation of a set of functional domains that are arranged in the nonstructural polyproteins in the following order (from $\mathrm{N}$ - to $\mathrm{C}$-terminus): two- $\beta$-barrel-fold main protease, RNA-dependent RNA polymerase of superfamily 1 (RdRp), zinc finger-containing helicase of superfamily 1 , and endoribonuclease. ${ }^{6-9}$ Despite their common ancestry, the nidovirus families differ considerably with regard to (i) their genome sizes (ranging from 12.7 to 31.3 kilobases), (ii) their structural proteins, and (iii) the conservation of several RNA-processing enzymes. $^{3}$

\section{ORGANIZATION AND EXPRESSION OF THE CORONAVIRUS REPLICASE GENE}

With genome sizes of between 27.3 and 31.3 kilobases, coronaviruses represent the largest nonsegmented RNA viruses currently known. About two-thirds of their genomes ( $>20,000$ nucleotides) are devoted to encoding the viral replicase, which mediates viral RNA synthesis but probably has many more functions. The replicase is encoded by the replicase gene. This gene is composed of two large open reading frames (ORFs), designated ORF1a and ORF1b, that are located at the 5'-end of the genome. The upstream ORF1a encodes a polyprotein of 450-500 kDa, termed polyprotein (pp) 1a, whereas ORF1a and ORF1b together encode pplab (750-800 kDa) (Fig. 1). Expression of the C-terminal ORF1b-encoded portion of pplab depends on a $(-1)$ ribosomal frameshift. As a consequence, the key replicative enzymes (RdRp, helicase, and others) are expressed at a significantly lower level than are ORF1a-encoded protein functions. ${ }^{5,10}$ The coronavirus replication complex is bound to intracellular membranes through several ORF1a-encoded hydrophobic domains (reviewed in Refs. 3 and 9) and, besides replicase

*University of Würzburg, D-97078 Würzburg, Germany and Queen's University, Belfast, United Kingdom, BT9 7BL 
gene-encoded proteins, includes several cellular proteins and the viral nucleocapsid protein. $^{11-13}$

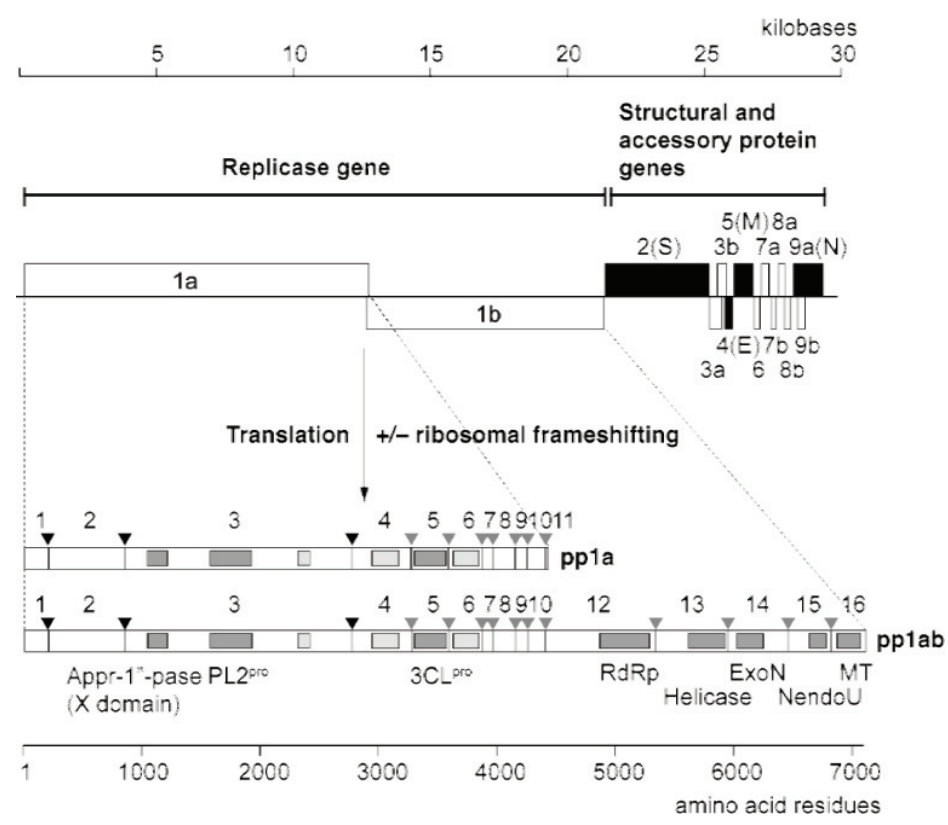

Figure 1. SARS-CoV genome organization. The putative functional open reading frames (ORFs) in the 29.7-kb genome of SARS-CoV are indicated (reviewed in Ref. 14). Translation of the genomic RNA gives rise to two replicative polyproteins, ppla and pplab, that mediate the key functions required for SARS-CoV genome replication and synthesis of 8 major subgenomic RNAs encoding the structural proteins (shown in black) and several SARS-CoV-specific accessory proteins. Expression of ORF1b sequences requires a programmed ribosomal frameshift into the -1 reading frame during translation of the genome RNA, which occurs just upstream of the ORF1a translation stop codon. The replicative polyproteins are extensively processed by viral proteases. The processing end-products of ppla are designated nonstructural proteins (nsp) 1 to nsp11 and those of pplab are designated nsp1 to nsp10 and nsp12 to nsp16. Cleavage sites that are processed by the 3C-like protease $\left(3 \mathrm{CL}^{\text {pro }}\right)$, which is also called main protease $\left(\mathrm{M}^{\mathrm{pro}}\right)$, are indicated by gray arrowheads, and sites that are processed by the papain-like protease, PL2 $2^{\text {pro }}$, are indicated by black arrowheads. The major replicative domains are shown in dark gray and transmembrane domains predicted to anchor the viral replicase to intracellular membranes are indicated in light gray. Appr-1"-pase, ADP-ribose 1"-phosphatase; PL2 ${ }^{\text {pro }}$, papain-like cysteine protease 2; 3CL pro $3 \mathrm{C}$-like main protease; RdRp, RNA-dependent RNA polymerase; ExoN, 3'-to-5' exoribonuclease; NendoU, nidoviral uridylate-specific endoribonuclease; MT, putative ribose-2'-O methyltransferase.

\section{PROTEASES AND PROTEOLYTIC PROCESSING}

Activation of the coronavirus replication complex involves extensive proteolytic processing of the replicase polyproteins to produce 16 (in IBV: 15) mature products called nonstructural proteins (nsp) 1 to 16 (reviewed in Refs. 3 and 15). The processing involves two different types of proteases. The key enzyme is the so-called 3C-like protease $\left(3 \mathrm{CL}^{\text {pro }}\right)$, also called main protease $\left(\mathrm{M}^{\text {pro }}\right)$, which cleaves the central and 
C-terminal regions of ppla and pplab at 11 conserved sites. ${ }^{15} 3 \mathrm{CL}^{\text {pro }}$ is a cysteine protease featuring a Cys-His catalytic dyad and a three-domain structure. ${ }^{16,17}$ The Nterminal domains I and II adopt a two- $\beta$-barrel-fold structure that resembles the structures of serine proteases of the chymotrypsin superfamily. The C-terminal entirely $\alpha$-helical domain III is critically involved in proteolytic activity and dimerization. It is now generally accepted that the $3 \mathrm{CL}^{\text {pro }}$ dimer represents the active form of the protease. ${ }^{18,19}$ Intermolecular interactions within the dimer have been suggested to keep the active center (in particular, the S1 subsite) in a proteolytically competent conformation. ${ }^{17,20}$ Coronavirus main proteases have conserved substrate specificities [(L,I)-Q $\downarrow$ (S,A,G)] and, accordingly, similar substrate-binding pocket structures, as has been shown by crystal structure analyses of main proteases from different coronavirus genetic groups. ${ }^{17,21-23}$ Based on this information, protease inhibitors have been developed that effectively inhibit a broad range of coronavirus main proteases. ${ }^{23}$ Potentially, these compounds may be useful for treatment of known or newly emerging coronavirus infections.

The N-terminal regions of the coronavirus polyproteins, which are poorly conserved among the coronavirus groups I, II, and III, are cleaved at two (in IBV) or three sites (in all other coronaviruses) by one (IBV and SARS-CoV) or two zinc-finger-containing papain-like cysteine proteases called $\mathrm{PL1}^{\text {pro }}$ and PL2 ${ }^{\text {pro }} \cdot{ }^{24-32} \mathrm{PL}^{\text {pro }}$ cleavage sites are usually flanked by small residues (mainly Gly and Ala). ${ }^{15} \mathrm{PL}^{\text {pro }}$ and PL2 ${ }^{\text {pro }}$ probably evolved by gene duplication in one of the ancestors of the present-day coronaviruses. ${ }^{29}$ For MHV, it was recently demonstrated that cleavage of the nsp1|nsp2 site and, even more suprisingly, the C-terminal nsp1 and the entire nsp2 sequence are not required for MHV replication in vitro. ${ }^{33-35}$

\section{POLYMERASE AND HELICASE ACTIVITIES}

The coronavirus RdRp has been classified as an outgroup of the RdRp superfamily $1{ }^{36}$ It resides in the ORF1b-encoded nonstructural proteins 12 , as was predicted about 15 years ago $^{6}$ and now demonstrated for a bacterially expressed form of the SARS-CoV nsp $12 .{ }^{37}$ The RdRp catalytic domain occupies the C-terminal two-thirds of nsp $12,{ }^{6}$ but also the N-terminal part of nsp12 seems to contribute to activity. ${ }^{37}$ Based on MHV coimmunoprecipitation data, the N-terminal part of nsp12 has been suggested to interact with other replicase subunits, specifically with nsp5 $\left(3 \mathrm{CL}^{\mathrm{pro}}\right), \mathrm{nsp} 8$, and nsp9 ${ }^{38}$ which is in line with the recently published crystal structure of an nsp7-nsp8 complex from SARS-CoV. ${ }^{39}$ The X-ray crystallography study by Zhai et al. ${ }^{39}$ provides first insights into the sophisticated architecture of the coronavirus replicase. It shows that eight molecules of each nsp7 and nsp8 assemble into a hexadecameric supercomplex that forms a hollow, cylinder-like structure, which, because of its internal dimensions and electrostatic properties, seems to be capable of encircling RNA. This nsp7-nsp8 supercomplex, in turn, interacts with nsp9, a small single-stranded RNA-binding protein, ${ }^{40,41}$ and interactions of nsp7-nsp8(-nsp9) with yet other replicase subunits (including nsp12) are likely. On the basis of structural and functional data, it has been speculated that the nsp7nsp8 complex might act as an important RdRp cofactor, for example, to increase the RdRp processivity. ${ }^{39}$ Evidence for a critical involvement of the C-terminal ppla processing products (nsp7-10) in viral RNA synthesis also comes from work on MHV 
temperature-sensitive mutants, which has shown that nsp10, a Cys/His-rich protein, has a distinct role in minus-strand RNA synthesis. ${ }^{42}$

After the RdRp, helicases are the second best conserved enzymes of plus-strand RNA viruses. The coronavirus helicase resides in nsp13 and has been classified as belonging to the helicase superfamily $1^{6,43}$ (Fig. 1). Coronavirus helicases and all their nidovirus homologs are linked to an N-terminal zinc-binding domain (ZBD) involving $12-13$ conserved Cys/His residues. ${ }^{6}$ The conservation of a ZBD-associated superfamily 1 helicase is considered one of the major genetic markers of nidoviruses. Over the past years, the helicase activities of HCoV-229E and, to a lesser extent, of SARS-CoV have been characterized. ${ }^{44-48}$ Mutagenesis and biochemical data revealed that the ZBD is essential for the enzymatic activities of both the coronavirus and arterivirus helicases. ${ }^{49}$ Coronavirus helicases proved to have multiple enzymatic activities, including nucleic acid-stimulated NTPase, dNTPase, and RNA (plus DNA) duplex-unwinding activities. ${ }^{44,47,48}$ Coronavirus (and arterivirus) helicases were demonstrated to unwind double-stranded RNA substrates with 5'-to-3' polarity, that is, they move in a 5'-to-3' direction along the strand to which they initially bind. ${ }^{44,50}$ The polarity of coronavirus helicase activities contrasts with that of the helicases of flavi-, pesti-, and hepaciviruses, which all operate in the opposite direction, ${ }^{51}$ indicating that the biological functions of helicases from the Nidovirales and Flaviviridae might differ fundamentally from each other. Coronavirus (nidovirus) helicases belong to the few helicases that act on both RNA or DNA substrates with nearly equal efficacy. Given that the helicase is part part of the (cytoplasmic) coronavirus replicase complex, it seems unlikely that the observed DNA duplex-unwinding activity is of biological significance. Coronavirus helicases are able to unwind up to several hundred base pairs of double-stranded nucleic acid in a processive manner, ${ }^{47,48}$ supporting a role as a "replicative" helicase that separates regions of doublestranded RNA that the polymerase might encounter during RNA synthesis.

Coronavirus helicases are able to hydrolyze essentially all natural nucleotides to fuel their translocation along nucleic acids and concomitant unwinding of duplex RNA (and DNA) structures. ${ }^{4-48}$ Besides their NTPase and dNTPase activities, coronavirus helicases were shown to possess yet another phosphohydrolyase activity, namely an RNA 5'triphosphatase activity that employs the active site of the (d)NTPase activity. It is reasonable to believe that the nsp13-associated RNA 5'-triphosphatase catalyzes the first reaction in the synthesis of coronavirus 5' RNA cap structures. ${ }^{47,48}$ Given the multiple enzymatic activities of coronavirus helicases and the previously observed diverse roles of the arterivirus helicase in viral replication, transcription and virion biogenesis, ${ }^{52}$ it is reasonable to believe that coronavirus helicases are involved in more than one metabolic pathway in the viral life cycle.

\section{RNA-PROCESSING ENZYMES}

A detailed sequence analysis by Gorbalenya, Snijder and colleagues of the SARS$\mathrm{CoV}$ genome revealed that the enzymology of coronavirus RNA synthesis may be significantly more complex than previously thought. ${ }^{8}$ In this seminal study published in 2003, as many as five novel enzymatic activities were identified in the genomes of coronaviruses and, to a varying extent, other nidoviruses (Fig. 1). The putative activities 
included (i) a 3'-to-5' exonuclease (ExoN) associated with nsp14, (ii) an endoribonuclease (NendoU) associated with nsp15, (iii) an S-adenosyl methionine-dependent ribose 2'-Omethyltransferase (MT) associated with nsp16, (iv) an ADP-ribose 1"-phosphatase (Appr-1"-pase) associated with the so-called "X domain" of nsp3, and (v) a cyclic phosphodiesterase (CPDase), which is only conserved in group II coronaviruses (excluding SARS-CoV). Four of the activities were found to be conserved in all coronaviruses, suggesting that they have an essential role in the coronaviral life cycle. Recently, the predicted exo- and endoribonuclease activities were established and characterized using bacterially expressed forms of the ExoN from SARS-CoV (Minskaia, Hertzig, Gorbalenya, Campanacci, Cambillau, Canard, and Ziebuhr, unpublished data), and the NendoU from $\mathrm{HCoV}-229 \mathrm{E}$, SARS-CoV, and IBV ${ }^{53,54}$ We have recently demonstrated by reverse genetics using the HCoV-229E infectious clone that the ExoN, NendoU, and MT domains are all essential for the production of virus progeny. Substitutions of predicted active-site residues resulted in diverse defects in viral RNA synthesis and virus production ${ }^{54}$ (Hertzig, Ulferts, Schelle, and Ziebuhr, unpublished data). The underlying mechanisms for the observed defects are currently being studied in detail.

The observed pattern of conservation in different nidovirus families suggests a functional hierarchy for the newly identified RNA-processing activities, with the manganese ion-dependent uridylate-specific endoribonuclease, NendoU, playing a central role. This enzyme is universally conserved in nidoviruses and, besides the ZBDassociated helicase, represents a genetic marker of nidoviruses that is also reflected by its previous designation as "nidovirus-specific conserved domain" ${ }^{55,56}$. As mentioned above, NendoU has been demonstrated by site-directed mutagenesis of the full-length HCoV$229 \mathrm{E}$ clone to be essential for coronaviral RNA synthesis. However, we recently obtained mutagenesis data that argue for a more complex scenario regarding the activities of NendoU. Thus, for example, we found that several single-residue substitutions that abolished the NendoU activity in an in vitro RNase assay gave rise to viable (albeit lowtiter) virus when transferred to the HCoV-229E infectious clone (Hertzig, Ulferts and Ziebuhr, unpublished data). These data indicate that NendoU might have more than one activity and/or cleave more than one substrate that likely differs from that used in our in vitro assays. Clearly, more work will be required to elucidate the function(s) of NendoU in the nidoviral life cycle.

In view of the very similar gene expression and RNA synthesis strategies employed by the various nidovirus families and genera, it is intriguing that only one (namely NendoU) of the newly identified nidovirus RNA-processing activities is conserved in arteriviruses. The basis for this differential conservation pattern of RNA-processing enzymes is currently unclear but might indicate that the enzymology involved in viral genome-length and subgenome-length RNA synthesis varies to some extent among the nidovirus families. Alternatively, members of the various nidovirus families/genera might interact differentially with yet-to-be-defined RNA-processing pathways of the host cell.

It is also worth remembering that arterivirus genomes are about 2 times smaller than other nidovirus genomes and it is possible that (some of) the extra domains conserved in corona- and toroviruses (and, to a lesser extent, in roniviruses) are required to replicate genomes of this unique size. The coronavirus ExoN activity was recently shown by sequence analysis and site-sirected mutagenesis to be related to cellular enzymes of the DEDD exonuclease superfamily (Minskaia, Hertzig, Gorbalenya, Campanacci, 
Cambillau, Canard, and Ziebuhr, unpublished data). This exonuclease family includes cellular 3'-to-5' exonucleases involved in proofreading, repair, and/or recombination, and it is tempting to speculate that nidoviruses use their ExoN domains in similar processes, for example, to keep the error frequency of their low-fidelity RdRp below a critical thereshold.

In contrast to the essential RNA-processing activities (ExoN, NendoU, and MT), the nsp3 X domain-associated Appr-1"-pase activity was found to be dispensable for viral replication in vitro. ${ }^{57}$ Substitutions of putative active-site residues of the Appr-1"-pase domain, which have been confirmed to abolish enzymatic activity in vitro, gave rise to viable virus. The virus had no apparent defects in viral RNA synthesis and grew to the same titers as the wild-type virus. ${ }^{57}$ Similarly, MHV reverse genetics data demonstrated that coronaviruses tolerate specific substitutions and even deletions in the replicase gene. For example, cleavage of the nsp1|nsp2 cleavage site was shown to be dispensable for viral replication, and even deletion of the C-terminal part of nsp1 and the entire nsp2, respectively, had only minor effects on viral replication. ${ }^{33-35}$ By contrast, several other mutations/deletions were tolerated in vitro but caused attenuation in the natural host. ${ }^{58}$ Taken together, the data suggest that coronavirus replicases have evolved to include a number of nonessential functions. The fact that some of the "nonessential" protease cleavages and enzymatic activities are conserved in coronaviruses or in specific coronavirus genetic groups suggests that they provide a selective advantage only in the host.

\section{CONCLUDING REMARKS}

Although much has been learned about coronavirus replicase organization, localization, proteolytic processing, and viral replicative enzymes, there are still major gaps in our knowledge. Inspired by the SARS epidemic in 2003, numerous studies aiming at the development of coronavirus vaccines and antivirals have recently been published, and there is no doubt that coronavirus research has gained momentum over the past few years. Given the rapidly accumulating biochemical, structural, and genetic information on coronaviruses, a more detailed understanding of the molecular mechanisms involved in coronaviral RNA synthesis can be expected to emerge in the near future. It will be of particular interest to identify those proteins that are involved in the specific mechanisms of coronavirus RNA synthesis, such as the production of a nested set of subgenome-length RNAs and the replication of RNA genomes of unprecedented size. Furthermore, studies on coronavirus-encoded RNA-processing activities and their cellular homologs might reveal interesting insights into the relationship (or interplay) of coronaviral and cellular RNA metabolism pathways. In the long run, the unique structural properties of several conserved coronavirus replicative enzymes may lead to the development of selective enzyme inhibitors and possibly even drugs suitable to treat coronavirus infections of humans and animals.

\section{ACKNOWLEDGMENT}

My work is supported by the Deutsche Forschungsgemeinschaft and the European Commission. 


\section{REFERENCES}

1. Cavanagh, D., 1997, Nidovirales: a new order comprising Coronaviridae and Arteriviridae, Arch. Virol. 142:629.

2. González, J. M., Gomez-Puertas, P., Cavanagh, D., Gorbalenya, A. E., and Enjuanes, L., 2003, A comparative sequence analysis to revise the current taxonomy of the family Coronaviridae, Arch. Virol. 148:2207.

3. Siddell, S. G., Ziebuhr, J., and Snijder, E. J., 2005, Coronaviruses, toroviruses, and arteriviruses, in: Topley and Wilson's Microbiology and Microbial Infections, 10th Edition, B. W. J. Mahy and V. ter Meulen, eds., Hodder Arnold, London, p. 823

4. Spaan, W., Delius, H., Skinner, M., Armstrong, J., Rottier, P., Smeekens, S., van der Zeijst, B. A., and Siddell, S. G., 1983, Coronavirus mRNA synthesis involves fusion of non-contiguous sequences, EMBO J. 2:1839.

5. Brierley, I., Boursnell, M. E., Binns, M. M., Bilimoria, B., Blok, V. C., Brown, T. D., and Inglis, S. C. 1987, An efficient ribosomal frame-shifting signal in the polymerase-encoding region of the coronavirus IBV, EMBO J. 6:3779.

6. Gorbalenya, A. E., Koonin, E. V., Donchenko, A. P., and Blinov, V. M., 1989b, Coronavirus genome: prediction of putative functional domains in the non-structural polyprotein by comparative amino acid sequence analysis, Nucleic Acids Res. 17:4847.

7. Gorbalenya, A. E., 2001, Big nidovirus genome. When count and order of domains matter, Adv. Exp. Med. Biol. 494:1.

8. Snijder, E. J., Bredenbeek, P. J., Dobbe, J. C., Thiel, V., Ziebuhr, J., Poon, L. L., Guan, Y., Rozanov, M., Spaan, W. J., and Gorbalenya, A. E., 2003, Unique and conserved features of genome and proteome of SARS-coronavirus, an early split-off from the coronavirus group 2 lineage, J. Mol. Biol. 331:991.

9. Ziebuhr, J., 2005, The coronavirus replicase, Curr. Top. Microbiol. Immunol. 287:57.

10. Herold, J., and Siddell, S. G., 1993, An 'elaborated' pseudoknot is required for high frequency frameshifting during translation of HCV 229E polymerase mRNA. Nucleic Acids Res 21:5838.

11. Almazán, F., Galán, C., and Enjuanes, L., 2004, The nucleoprotein is required for efficient coronavirus genome replication, J. Virol. 78:12683.

12. Schelle, B., Karl, N., Ludewig, B., Siddell, S. G., and Thiel, V., 2005, Selective replication of coronavirus genomes that express nucleocapsid protein, J. Virol. 79:6620.

13. Shi, S. T, and Lai, M. M., 2005, Viral and cellular proteins involved in coronavirus replication, Curr. Top. Microbiol. Immunol. 287:95.

14. Ziebuhr, J., 2004, Molecular biology of severe acute respiratory syndrome coronavirus, Curr. Opin. Microbiol. 7:412

15. Ziebuhr, J., Snijder, E. J., and Gorbalenya, A. E., 2000, Virus-encoded proteinases and proteolytic processing in the Nidovirales, J. Gen. Virol. 81:853.

16. Anand, K., Palm, G. J., Mesters, J. R., Siddell, S. G., Ziebuhr, J., and Hilgenfeld, R., 2002, Structure of coronavirus main proteinase reveals combination of a chymotrypsin fold with an extra alpha-helical domain, EMBO J. 21:3213.

17. Anand, K., Ziebuhr, J., Wadhwani, P., Mesters, J. R., and Hilgenfeld, R., 2003, Coronavirus main proteinase $\left(3 \mathrm{CL}^{\mathrm{pro}}\right)$ structure: basis for design of anti-SARS drugs, Science 300:1763.

18. Shi, J., Wei, Z., and Song, J., 2004, Dissection study on the severe acute respiratory syndrome 3C-like protease reveals the critical role of the extra domain in dimerization of the enzyme: defining the extra domain as a new target for design of highly specific protease inhibitors. J. Biol. Chem. 279:24765.

19. Hsu, W. C., Chang, H. C., Chou, C. Y., Tsai, P. J., Lin, P. I., and Chang, G. G., 2005, Critical assessment of important regions in the subunit association and catalytic action of the severe acute respiratory syndrome coronavirus main protease, J. Biol. Chem. 280:22741.

20. Chen, S., Chen, L., Tan, J., Chen, J., Du, L., Sun, T., Shen, J., Chen, K., Jiang, H., and Shen, X., 2005 Severe acute respiratory syndrome coronavirus $3 \mathrm{C}$-like proteinase $\mathrm{N}$ terminus is indispensable for proteolytic activity but not for enzyme dimerization. Biochemical and thermodynamic investigation in conjunction with molecular dynamics simulations, J. Biol. Chem. 280:164.

21. Hegyi, A., and Ziebuhr, J., 2002, Conservation of substrate specificities among coronavirus main proteases, J. Gen. Virol. 83:595.

22. Yang, H., Yang, M., Ding, Y., Liu, Y., Lou, Z., Zhou, Z., Sun, L., Mo, L., Ye, S., Pang, H., Gao, G. F., Anand, K., Bartlam, M., Hilgenfeld, R., and Rao, Z., 2003, The crystal structures of severe acute respiratory syndrome virus main protease and its complex with an inhibitor, Proc. Natl. Acad. Sci. USA 100: 13190 
23. Yang, H., Xie, W., Xue, X., Yang, K., Ma, J., Liang, W., Zhao, Q., Zhou, Z., Pei, D., Ziebuhr, J., Hilgenfeld, R., Yuen, K. Y., Wong, L., Gao, G., Chen, S., Chen, Z., Ma, D., Bartlam, M., and Rao, Z., 2005, Design of wide-spectrum inhibitors targeting coronavirus main proteases, PLoS Biol. 3:e324.

24. Baker, S. C., Yokomori, K., Dong, S., Carlisle, R., Gorbalenya, A. E., Koonin, E. V., and Lai, M. M., 1993 , Identification of the catalytic sites of a papain-like cysteine proteinase of murine coronavirus, J. Virol. 67:6056.

25. Herold, J., Gorbalenya, A. E., Thiel, V., Schelle, B., and Siddell, S. G., 1998, Proteolytic processing at the amino terminus of human coronavirus $229 \mathrm{E}$ gene 1-encoded polyproteins: identification of a papain-like proteinase and its substrate, J. Virol. 72:910.

26. Lim, K. P., and Liu, D. X., 1998, Characterization of the two overlapping papain-like proteinase domains encoded in gene 1 of the coronavirus infectious bronchitis virus and determination of the C-terminal cleavage site of an 87-kDa protein, Virology 245:303.

27. Kanjanahaluethai, A., and Baker, S. C., 2000, Identification of mouse hepatitis virus papain-like proteinase 2 activity, $J$. Virol. 74:7911.

28. Lim, K. P., Ng, L. F., and Liu, D. X., 2000, Identification of a novel cleavage activity of the first papain-like proteinase domain encoded by open reading frame la of the coronavirus Avian infectious bronchitis virus and characterization of the cleavage products, J. Virol. 74:1674.

29. Ziebuhr, J., Thiel, V., and Gorbalenya, A. E., 2001, The autocatalytic release of a putative RNA virus transcription factor from its polyprotein precursor involves two paralogous papain-like proteases that cleave the same peptide bond, J. Biol. Chem. 276:33220.

30. Thiel, V., Ivanov, K. A., Putics, Á., Hertzig, T., Schelle, B., Bayer, S., Weissbrich, B., Snijder, E. J., Rabenau, H., Doerr, H. W., Gorbalenya, A. E., and Ziebuhr, J., 2003, Mechanisms and enzymes involved in SARS coronavirus genome expression, J. Gen. Virol. 84:2305.

31. Harcourt, B. H., Jukneliene, D., Kanjanahaluethai, A., Bechill, J., Severson, K. M., Smith, C. M., Rota, P. A., and Baker, S. C., 2004, Identification of severe acute respiratory syndrome coronavirus replicase products and characterization of papain-like protease activity, J. Virol. 78:13600

32. Han, Y. S., Chang, G. G., Juo, C. G., Lee, H. J., Yeh, S. H., Hsu, J. T., and Chen, X., 2005, Papain-like protease 2 (PLP2) from severe acute respiratory syndrome coronavirus (SARS-CoV): expression, purification, characterization, and inhibition, Biochemistry 44:10349.

33. Denison, M. R., Yount, B., Brockway, S. M., Graham, R. L., Sims, A. C., Lu, X., and Baric, R. S., 2004 Cleavage between replicase proteins p28 and p65 of mouse hepatitis virus is not required for virus replication, J. Virol. 78:5957.

34. Brockway, S. M., and Denison, M. R., 2005, Mutagenesis of the murine hepatitis virus nsp1-coding region identifies residues important for protein processing, viral RNA synthesis, and viral replication, Virology 340:209.

35. Graham, R. L., Sims, A. C., Brockway, S. M., Baric, R. S., and Denison, M. R., 2005, The nsp2 replicase proteins of murine hepatitis virus and severe acute respiratory syndrome coronavirus are dispensable for viral replication, J. Virol. 79:13399.

36. Koonin, E. V., 1991, The phylogeny of RNA-dependent RNA polymerases of positive-strand RNA viruses, J. Gen. Virol. 72:2197.

37. Cheng, A., Zhang, W., Xie, Y., Jiang, W., Arnold, E., Sarafianos, S. G., and Ding, J., 2005, Expression, purification, and characterization of SARS coronavirus RNA polymerase, Virology 335: 165

38. Brockway, S. M., Clay, C. T., Lu, X. T., and Denison, M. R., 2003, Characterization of the expression, intracellular localization, and replication complex association of the putative mouse hepatitis virus RNAdependent RNA polymerase, J. Virol. 77:10515.

39. Zhai, Y., Sun, F., Li, X., Pang, H., Xu, X., Bartlam, M., and Rao, Z., 2005, Insights into SARS-CoV transcription and replication from the structure of the nsp7-nsp8 hexadecamer, Nat. Struct. Mol. Biol. Epub ahead of print

40. Egloff, M. P., Ferron, F., Campanacci, V., Longhi, S., Rancurel, C., Dutartre, H., Snijder, E. J., Gorbalenya, A. E., Cambillau, C., and Canard, B., 2004, The severe acute respiratory syndrome-coronavirus replicative protein nsp9 is a single-stranded RNA-binding subunit unique in the RNA virus world, Proc. Natl. Acad. Sci. USA 101:3792.

41. Sutton, G., Fry, E., Carter, L., Sainsbury, S., Walter, T., Nettleship, J., Berrow, N., Owens, R., Gilbert, R., Davidson, A., Siddell, S., Poon, L. L., Diprose, J., Alderton, D., Walsh, M., Grimes, J. M., and Stuart, D. I., 2004, The nsp9 replicase protein of SARS-coronavirus, structure and functional insights, Structure (Camb) 12:341.

42. Siddell, S., Sawicki, D., Meyer, Y., Thiel, V., and Sawicki, S., 2001, Identification of the mutations responsible for the phenotype of three MHV RNA-negative ts mutants, Adv. Exp. Med. Biol. 494:453. 
43. Gorbalenya, A. E., Koonin, E. V., Donchenko, A. P., and Blinov, V. M., 1989a, Two related superfamilies of putative helicases involved in replication, recombination, repair and expression of DNA and RNA genomes, Nucleic Acids Res. 17:4713.

44. Seybert, A., Hegyi, A., Siddell, S. G., and Ziebuhr, J., 2000a, The human coronavirus 229E superfamily 1 helicase has RNA and DNA duplex-unwinding activities with 5'-to-3' polarity, RNA 6:1056.

45. Seybert, A., and Ziebuhr, J., 2001, Guanosine triphosphatase activity of the human coronavirus helicase, Adv. Exp. Med. Biol. 494:255

46. Tanner, J. A., Watt, R. M., Chai, Y. B., Lu, L. Y., Lin, M. C., Peiris, J. S., Poon, L. L., Kung, H. F., and Huang, J. D., 2003, The severe acute respiratory syndrome (SARS) coronavirus NTPase/helicase belongs to a distinct class of '5' to 3' viral helicases, J. Biol. Chem. 278:39578.

47. Ivanov, K. A., Thiel, V., Dobbe, J. C., van der Meer, Y., Snijder, E. J., and Ziebuhr, J., 2004b, Multiple enzymatic activities associated with severe acute respiratory syndrome coronavirus helicase, J. Virol. 78:5619.

48. Ivanov, K. A., and Ziebuhr, J., 2004, Human coronavirus 229E nonstructural protein 13: characterization of duplex-unwinding, nucleoside triphosphatase, and RNA 5'-triphosphatase activities, J. Virol. 78:7833.

49. Seybert, A., Posthuma, C. C., van Dinten, L. C., Snijder, E. J., Gorbalenya, A. E., and Ziebuhr, J., 2005, A complex zinc finger controls the enzymatic activities of nidovirus helicases, J. Virol. 79:696.

50. Seybert, A., van Dinten, L. C., Snijder, E. J., and Ziebuhr, J., 2000b, Biochemical characterization of the equine arteritis virus helicase suggests a close functional relationship between arterivirus and coronavirus helicases, J. Virol. 74:9586.

51. Kadaré, G., and Haenni, A. L., 1997, Virus-encoded RNA helicases, J. Virol. 71:2583.

52. van Dinten, L. C., van Tol, H., Gorbalenya, A. E., and Snijder, E. J., 2000, The predicted metal-binding region of the arterivirus helicase protein is involved in subgenomic mRNA synthesis, genome replication, and virion biogenesis, J. Virol. 74:5213.

53. Bhardwaj, K., Guarino, L., and Kao, C. C., 2004, The severe acute respiratory syndrome coronavirus Nsp15 protein is an endoribonuclease that prefers manganese as a cofactor, J. Virol. 78:12218

54. Ivanov, K. A., Hertzig, T., Rozanov, M., Bayer, S., Thiel, V., Gorbalenya, A. E., and Ziebuhr, J., 2004a, Major genetic marker of nidoviruses encodes a replicative endoribonuclease, Proc. Natl. Acad. Sci. USA 101:12694.

55. Snijder, E. J., den Boon, J. A., Bredenbeek, P. J., Horzinek, M. C., Rijnbrand, R., and Spaan, W. J., 1990, The carboxyl-terminal part of the putative Berne virus polymerase is expressed by ribosomal frameshifting and contains sequence motifs which indicate that toro- and coronaviruses are evolutionarily related, Nucleic Acids Res. 18:4535.

56. den Boon, J. A., Snijder, E. J., Chirnside, E. D., de Vries, A. A., Horzinek, M. C., and Spaan, W. J., 1991, Equine arteritis virus is not a togavirus but belongs to the coronaviruslike superfamily, J. Virol. 65:2910.

57. Putics, A., Filipowicz, W., Hall, J., Gorbalenya, A. E., and Ziebuhr, J., 2005, ADP-ribose-1"monophosphatase: a conserved coronavirus enzyme that is dispensable for viral replication in tissue culture, J. Virol. 79:12721.

58. Sperry, S. M., Kazi, L., Graham, R. L., Baric, R. S., Weiss, S. R., and Denison, M. R., 2005, Single-aminoacid substitutions in open reading frame (ORF) 1 b-nsp14 and ORF 2a proteins of the coronavirus mouse hepatitis virus are attenuating in mice, J. Virol. 79:3391. 